\title{
Diabetes mellitus and optic atrophy: Study of the Wolfram syndrome
}

\author{
Bernardette Rivas-Gómez and Alfredo Adolfo Reza-Albarrán
}

Departments of Internal Medicine and Endocrinology, Instituto Nacional de Ciencias Médicas y Nutrición Salvador Zubirán, Ciudad de México, Mexico

\begin{abstract}
Background: Wolfram syndrome (WS), also known by the acronym diabetes insipidus, diabetes mellitus, optic atrophy, and deafness (DIDMOAD), is a rare and progressive hereditary disease of autosomal recessive inheritance which minimum ascertainment diagnostic criteria are the occurrence together of diabetes mellitus and optic atrophy before 15 years of age. Objective: The objective of the study was to describe the clinical, biochemical and molecular profile of WS in a tertiary care hospital in Mexico. Methods: We reviewed patients records who fulfill the minimum ascertainment diagnostic criteria of WS presenting between January 1987 and May 2015 in a tertiary care hospital in Mexico. Results: Five patients fulfill the inclusion criteria (three male and two female). Diabetes mellitus was the first manifestation of the syndrome in all of them, with a mean age at diagnosis of $5.8 \pm 2.71$ years, while the WS diagnosis was established at a mean age of $15.8 \pm 8.37$ years. All the patients had optic atrophy, and two of them presented with the complete DIDMOAD spectrum. We found new associations with autoimmune hepatitis and testicular cancer. Conclusions: This study shows the variability of clinical presentation of WS, as well as two new associations.
\end{abstract}

KEY WORDS: Wolfram syndrome. Diabetes insipidus, Oiabetes mellitus, Optic atrophy, and deafness. Endoplasmic reticulum. Diabetes mellitus. Optic atrophy.

\section{Introduction}

Wolfram syndrome (WS) (MIM 222300), which was first described in 1938 by Wolfram and Wagener ${ }^{1}$, is also known as diabetes insipidus, diabetes mellitus, optic atrophy, and deafness (DIDMOAD), although many propose that it should be called DIDMOADUD, with the latter two initials referring to the high-frequency urinary dysfunction occurs ${ }^{2,3}$.

Initially, deletions or mutations in the mitochondrial genome (mtDNA) were thought to be the causes of this syndrome due to the phenotypical similarities of patients with WS and with mitochondrial conditions ${ }^{4-6}$; however, the presence of affected and unaffected children from healthy parents, frequently blood-related, suggested a recessive autosomal inheritance mode with incomplete penetrance and variable expresivity? It was until 1998 that the WFS1 gene, which causes WS, was identified at chromosome $4 \mathrm{p} 16.1^{8}$. This gene comprises 8 exons and encodes a tetrameric protein called wolframine, which is formed by 890 amino acids and is located at the endoplasmic reticulum (ER) membrane, with high expression values in the brain, the pancreas, the heart and skeletal muscle ${ }^{9}$.

The protein synthesis, folding, and transport rate is coordinated by an efficient quality control system, which ensures that only adequately folded proteins can leave the ER to exert their biological function ${ }^{10}$. Inadequately folded proteins are retained in the ER or undergo degradation. ER homeostasis is defined as a state of balance between cell demand for protein synthesis and ER folding capability to promote protein

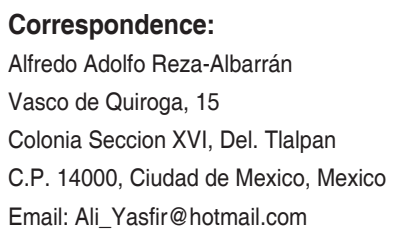

Date of reception: 03-02-2016

Date of acceptance: 19-04-2016 DOI: 10.24875/GMM.M17000025
Gac Med Mex. 2017;153:427-432

Contents available at PubMed www.gacetamedicademexico.com 
transport and maturation to satisfy such demand ${ }^{11}$. Unfolded or defectively folded proteins have a deleterious effect on cell function and can cause their death, a process that is known as proteotoxicity or ER stress ${ }^{10,12-15}$.

To maintain ER homeostasis, cells have developed an adaptive mechanism of response to stress, known as unfolded protein response (UPR), which comprises a series of intracellular signaling pathways to confront metabolic, oxidative and inflammatory stress ${ }^{10,16,17}$. UPR has the capacity to act as a binary switch between life and death since it can regulate both survival and apoptotic effectors ${ }^{18}$. There are two types of stress on the cell: tolerable (which the cell is able to solve) and intolerable stress. When stress is solvable, all the cascades and mechanisms to promote survival are set in motion, whereas when the UPR detects a stress that it is not able to resolve, or when its mechanisms are unable to restore ER homeostasis in the presence of chronic stressors, there is a UPR hyperactivation that triggers the action of cell death effectors, which lead to apoptosis ${ }^{11}$.

Wolfram in is an important component of UPR survival pathway ${ }^{10,18}$. In WS, Wolfram in deficiency causes hyperactivation and uncontrolled rise of cell signaling pathways that cause death by apoptosis in sensitive cells ${ }^{11,19}$.

Clinical and genetic studies have demonstrated that inherited or acquired ER dysfunction is the cause or contributor to the onset of diseases that are much more common than WS, such as type 1 and 2 diabetes mellitus, obesity, atherosclerosis, dyslipidemia, hepatic steatosis, and many different types of cancer and neurodegenerative conditions such as Alzheimer's disease, Huntington's chorea, and prion diseases, which makes the ER an attractive therapeutic target for these diseases ${ }^{10,20-23}$; however, WS is regarded as the prototype of ER diseases.

The prevalence of WS is estimated at 1 per 770,000 people in the United Kingdom, with a carrier prevalence of 1 in $354^{24}$, at 1 in 710,000 in the Japanese population ${ }^{25}$, and 1 in 805,000 in India ${ }^{26}$. Higher prevalences have been described, such as 1 in 68,000 people in Lebanon ${ }^{27}$, which is partially attributed to the high rates of blood-relatedness in this region.

WS diagnosis continues to be clinical, with mutational analysis being used to confirm the diagnosis ${ }^{4}$. Minimal criteria for diagnosis are diabetes mellitus and optic atrophy, both with onset before 15 years of age, with a positive predictive value of $83 \%$ and negative of $1 \%^{24}$.
The late presentation, with diabetes and optic atrophy onset after 15 years of age, is highly variable in frequency between different cohorts; however, these differences may be due to underdiagnosis of patients with WS older than 15 years and to a difference in the distinct series in the study of atypical phenotypes ${ }^{6,28-30}$.

Average age of death for WS patients is 30 years, and the main cause of death is respiratory failure caused by brainstem atrophy ${ }^{31}$. Other important causes of morbidity and mortality include urinary tract infections and chronic renal failure.

There is very limited published information on WS in Mexico. Knowing these data will help to optimize the infrastructure for the study and management of patients with WS and likely favorably influence on their diagnosis, evolution, quality of life, rehabilitation, and prognosis.

In this study, we describe the clinical, biochemical and molecular (when the latter was available) characteristics of WS in a tertiary care hospital.

\section{Methods}

This was a retrospective, cross-sectional, and descriptive study. The medical records department was requested a list of patients with diagnoses of diabetes associated with optic atrophy (according to ICD 10 codes) in the period comprised between January 1 , 1987, and May 31, 2015. The records were reviewed, and those where WS had already been ruled out, as well as those where optic atrophy was attributed to any cause other than WS, were excluded. The information was captured in a database, and the variables were analyzed using STATA, version 13.

\section{Results}

After the search for medical records containing diagnoses of diabetes and optic atrophy, 11 records were obtained, out of which 6 were excluded according to the exclusion and elimination criteria. We included the remaining 5 patients and reviewed their medical records for data collection and analysis. Out of these, $40 \%$ were found to correspond to females $(n=2)$ and $60 \%$ to males $(n=3)$. Average age at diabetes diagnosis was $5.8 \pm 2.71$ years, and in all cases, it was the first manifestation of the syndrome.

Average age at optic atrophy diagnosis was $12.2 \pm$ 6.37 years, while the WS diagnosis was established on average at $15.8 \pm 8.37$ years of age. 
Table 1. Study variables divided by gender

\begin{tabular}{lccr}
\hline Variable & & Mean (SD) & \\
\cline { 2 - 4 } & Males and females & Males & Females \\
\hline Weight $(\mathrm{kg})$ & $55.34(11.27)$ & $58(15.71)$ & $51.35(9.40)$ \\
Height (meters) & $1.58(0.092)$ & $1.64(0.069)$ & $1.50(0.098)$ \\
BMl (kg/m²) & $21.74(2.61)$ & $21.2(3.93)$ & $22.55(1.06)$ \\
Age at DM diagnosis (years) & $5.8(2.71)$ & $7(2)$ & $4(4.24)$ \\
Age at OA diagnosis (years) & $12.2(6.37)$ & $11(5.19)$ & $14(9.89)$ \\
Age at WS diagnosis (years) & $15.8(8.37)$ & $10(7)$ & $24.5(0.70)$ \\
DM evolution time (years) & $18.8(4.26)$ & $16.3(1.52)$ & $22.5(6.36)$ \\
Glycosylated hemoglobin (\%) & $8.44(1.31)$ & $7.53(0.49)$ & $9.8(1.41)$ \\
\hline BMl: body mass index: DM: diabetes mellitus: OA: optic atrophy: SD: standard deviation: WS: wolfram syndrome. & &
\end{tabular}

None of the patients included in this study had a history of blood-relatedness or a hereditary or family history suggestive of WS on past generations.

None of the patients was at diabetes control goals; last glycosylated hemoglobin average was $8.44 \%$ (7.2-10.8\%), and all were under intensive insulin regimen with 3 or more injections per day and with average doses of 0.64 units $/ \mathrm{kg}$, with a range of $0.29-0.64$ units $/ \mathrm{kg}$.

Study subjects' average body mass index was $21.74 \pm 2.92 \mathrm{~kg} / \mathrm{m}^{2}$. Table 1 summarizes some of the study variables divided by gender.

Of the 5 patients, 2 had a central diabetes insipid us diagnosis, 3 had moderate to serious hearing impairment, 4 had at least some neurodegenerative alteration, 4 showed psychiatric manifestations, 5 had urological disorders, 5 had endocrine alterations, and 3 had gastrointestinal abnormalities. Two of the patients had the full DIDMOAD spectrum, and all 5 were still alive at the moment of the study, and mortality could, therefore, not be studied.

Only one patient had a neuroimaging study, a cranial computed tomography without contrast that showed no abnormalities and that had been ordered for reasons other than WS.

\section{Discussion}

WS is a rare condition with great phenotypic pleomorphism. Diabetes in WS is insulin-deficient, similar to type 1 diabetes mellitus, but it is not autoimmune and not linked to the major histocompatibility complex. Its cause is a selective degeneration of beta cells that starts practically since birth, and for this reason it's onset is often at earlier ages than diabetes of autoimmune cause, with an average age at diagnosis of 6 years $^{32,33}$, similar to that which was observed in our population, where the age at diagnosis was $5.8 \pm 2.71$ years. As in all our patients, it is often the syndrome's first manifestation in up to $80 \%$ of cases. None of the patients in this study had antibody determination to rule out the autoimmune origin.

Different studies have demonstrated a slower progression of diabetes, with a lower incidence of microvascular complications, diabetic ketoacidosis, and glycemic variability, as well as lower insulin requirements in comparison with patients with type 1 diabetes ${ }^{17,34,35}$. In our study, only one female patient had a history of a diabetic ketoacidosis episode, and only 2 patients had any microvascular complication documented (non-proliferative diabetic retinopathy), in spite of having a diabetes evolution average time of $18.8 \pm 4.26$ years. No patient had diabetic nephropathy diagnosis according to an albuminuria determination of follow-up last year.

Although cases of optic atrophy have been described with age ranges as broad as 6 weeks to 30 years $^{3,36}$, it is diagnosed at an average 11 years of age, and it causes amaurosis approximately 8 years after diagnosis. In our study, average age at diagnosis was $12.2 \pm 6.37$ years, and three patients already had amaurosis; similar to most patients in other series, it was the syndrome's second manifestation. As for other ophthalmologic alterations, only one case bilateral cataract was found in one female patient.

Central diabetes insipidus, secondary to the hypothalamus and posterior pituitary neurodegenerative process, occurs in $51-87 \%$ of patients with WS, with 
an average age at diagnosis of 14 years and with polyuria being its first clinical manifestation ${ }^{37-39}$. In this study, 2 patients (40\%) had central diabetes insipid us, with an average age at diagnosis of 17 years; both were on treatment with desmopressin.

Depending on the series, hearing alterations occur in $62-100 \%$ of patients with WS ${ }^{30,40}$. Hearing loss is usually slowly progressive, and it affects especially high frequencies, between 250 and $2000 \mathrm{~Hz}$, which makes for its diagnosis to be made at late stages ${ }^{41,42}$. In this study, 4 of the 5 patients had an audiometric study available, and 3 of them (60\%) had moderate to serious hearing loss, with an average age of 16.6 years at diagnosis.

Very little is known so far about the broad neurological alterations spectrum in patients with WS. Previously, these alterations were thought to begin at the third decade of life; however, today, its onset is known to occur at much earlier ages ${ }^{43-45}$.

Neurological complications are the main cause of death in patients with WS, and their spectrum includes central apnea, ataxia of the trunk, peripheral neuropathy, loss of the gag reflex predisposing to bronchospasm, myoclonus, loss of the senses of smell and taste, epilepsy, and nystagmus ${ }^{46-48}$. In our study, some neurodegenerative alteration was described in 4 of 5 patients, with an average age at diagnosis of the first manifestation of $14.25 \pm 7.45$ years, and with seizures being the most common manifestation $(n=2)$. Other alterations described in the patients of this study are peripheral neuropathy, myoclonus, postural tremor, anosmia, and cognitive disturbances; these were found only in one patient each.

Psychiatric disorders observed in patients with WS are quite diverse. Depressive disorder is the psychiatric alteration most commonly found in all series, including ours (80\%); however, violent and aggressive behavior, anxiety, psychosis, bipolar disorders, and impulsive behaviors are also common findings. The psychiatric diagnosis can vary over time in the same patient ${ }^{49,50}$.

The WFS1 gene is suggested to play a role in the neuropsychopathology of suicide and can be a biomarker of post-traumatic stress ${ }^{50,51}$; high rates of this gene among patients with WS make psychiatric evaluation mandatory. In our series, all patients had been attended to at the psychiatry outpatient clinic, and $40 \%$ had a previous history of at least two suicide attempts; in all cases, insulin was used as a method to attempt suicide. People who are homozygous, as well as those who are heterozygous for mutations in WFS1, have an increased suicide risk ${ }^{50}$.

Urologic alterations occur in approximately 58$100 \%$ of patients and initially were attributed to a high urinary output secondary to diabetes insipid us and hyperglycemia; however, the persistence in urinary tract dilatation in spite of diabetes insipid us control and available evidence from urodynamic studies have demonstrated that bladder dysfunction is the main cause of hydroureteronephrosis observed in these patients ${ }^{3,30,40}$. In our series, $100 \%$ of patients had at least one urologic alteration, with neurogenic bladder being the most common $(n=3)$, with an average age at diagnosis of $13.4 \pm 5.68$ years; two patients have bladder catheterization as part of their treatment.

Gonadal alterations are frequently observed in male patients and very rarely and in mild forms in females ${ }^{37}$. The reason why this alteration is practically exclusive to the male gender has not yet been possible to be clarified.

In females, the ovarian function is preserved, and only mild or moderate menstrual alterations have been reported, as it occurred in both females included in this study; however, there are many cases of women with WS who have had full-term pregnancies, with no complications and healthy children ${ }^{43,52}$. In this series, both females had menstrual irregularities; both were nulligravidae and had no hormone profile for analysis. As another endocrine alteration, both study female subjects had been diagnosed with hypothyroidism and were on replacement treatment with levothyroxine at the time of the study.

Hypogonadotropic or hypergonadotropic hypogonadism symptoms occur in approximately $34 \%$ of males with $\mathrm{WS}^{17}$, including delayed puberty, testicular atrophy that causes alterations in the shape of spermatozoids and a reduced number of spermatogenic cells, in addition to erectile dysfunction, among oth$\mathrm{ers}^{53}$. In this study, $100 \%$ of males $(\mathrm{n}=3)$ had hypergonadotropic hypogonadism diagnosed by laboratory tests.

Testicular cancer (classic seminoma), documented in one of our patients, had not been previously reported in association with WS.

Up to $25 \%$ of patients exhibit gastrointestinal motility alterations, although often they go unnoticed. The symptomatic spectrum includes gastroparesis, incontinence due to sphincter weakness, diarrhea and constipation, and secondary to myenteric plexus cells neurodegeneration ${ }^{26,33,54}$. In this series, two patients had chronic constipation, while one was diagnosed 
with autoimmune hepatitis by serology and biopsy, an association not previously described in the literature.

International series have reported a high number of heart conditions, with valve alterations, interventricular septum defects, tetralogy of Fallot and arrhythmias standing out, and with paroxysmal supraventricular tachycardia being the most common ${ }^{3,27,38}$. In this study, no patient had any diagnosed heart condition.

More than $90 \%$ of patients with WS have some mutation in one or both alleles of the WFS1 gene. In those in whom no mutation has been identified, there is the possibility for it to be found in the promoter (which has not yet been encoded), in intronic sequences or in non-encoding exon 1, since they were not searched for in most studies ${ }^{4,41,55}$.

So far, more than 200 different mutations of the WFS1 gene have been described. Most mutations are unique to an individual or family, and its private nature makes it therefore very difficult for a clear genotype-phenotype relationship to be outlined ${ }^{32,56,57}$. Mutations are randomly distributed throughout the encoding sequence of the gene, but up to $80 \%$ of mutations so far reported are found at exon $8^{25,26,30,31,37,56-59}$.

In this study, $60 \%$ of patients $(n=3)$ had a molecular diagnosis available; they are three brothers (all 3 males of the study) who exhibit two heterozygous state mutations: the first one, inherited from the father, is a guanine transition for cytokine at codon 177 that changes an arginine for a proline at exon 5 , and the second is a maternal-inheritance deletion of $16 \mathrm{bp}$ (P451fs X515) at exon 8 that changes the reading frame and generates a premature termination codon at the protein normal sequence. These mutations had already been previously described in this family by Zenteno et al. ${ }^{60}$ in 2008.

Follow-up studies suggest that patients with WS eventually develop the full spectrum of the disease if they live enough. Many patients with WS can remain undiagnosed until adulthood owing to a type 1 diabetes misdiagnosis and wrongful interpretation of neurodegenerative alterations clinical symptoms, especially at early stages, by attributing them to diabetes complications $^{43}$. To date, there is no intervention that alters disease progression or prolongs life expectancy in WS, but early recognition of this syndrome and its complications may increase the quality of life of those who suffer from it by enabling early interventions for the components of this syndrome ${ }^{22}$.

Although WS is a rare disease, it should be suspected in all those cases of diabetes mellitus with symptoms of progressive optic atrophy, hearing loss, diabetes insipidus, psychiatric symptoms, or urinary tract alterations ${ }^{43,61}$.

\section{References}

1. Wolfram DJ, Wagener HP. Diabetes mellitus and simple optic atrophy among siblings: report of four cases. Mayo Clin Proc. 1938;13:715-8.

2. Rigoli L, Lombardo F, Di Bella C. Wolfram syndrome and WSF1 gene. Clin Genet. 2011;79:103-17.

3. Kumar S. Wolfram syndrome: important implications for pediatricians and pediatric endocrinologists. Pediatric Diabetes. 2010;11:28-37.

4. Khanim F, Kirk J, Latif F, et al. WFS1/Wolframin mutations, Wolfram syndrome, and associated diseases. Human Mutation. 2001;17:357-67.

5. Barret TG. Mitocondrial diabetes, DIDMOAD and other inherited diabetes syndromes. Best Pract Res Clin Endocrinol Metab. 2001;15:325-43.

6. Gómez-Zaera M, Strom TM, Rodríguez B, et al. Presence of a major WFS1 mutation in Spanish Wolfram syndrome pedigries. Mol Genet Metabol. 2001;72:72-81.

7. Fraser FC, Gunn T. Diabetes mellitus, diabetes insipidus, and optic atrophy. An autosomal recessive syndrome? J Med Genet. 1977;14:190-3.

8. Inoue $\mathrm{H}$, Tanizawa $\mathrm{Y}$, Wasson $\mathrm{J}$, et al. A gene encoding a transmembrane protein is mutated in patients with diabetes mellitus and optic atrophy (Wolfram syndrome). Nat Genet. 1998;20:143-8.

9. Hofmann S, Philbrook C, Gerbitz KD, et al. Wolfram syndrome: structural and functional analisys of mutante and wild-type wolframin, the WFS1 gene product. Hum Mol Genet. 2003;12:2003-12.

10. Wang S, Kaufman RJ. The impact of the unfolded protein response on human disease. J Cell Biol. 2012;197:857-67.

11. Fonseca SG, Gromada J, Urano F. Endoplasmic reticulum stress and pancreatic b-cell death. Trends Endocrinol Metabol. 2011;22:266-74.

12. Zatyka M, Da Silva XG, Bellomo EA, et al. Sarco(endo)plasmic reticulum ATPase is a molecular partner of Wolfram syndrome 1 protein, wich negatively regulates its expression. Hum Mol Genet. 2015;24:814-27.

13. Fonseca SG, Burcin M, Gromada J, et al. Endoplasmic reticulum stress in b-cells and development of diabetes. Curr Opin Pharmacol. 2009;9:763-70.

14. Araki E, Oyadomari S, Mori M. Endoplasmic reticulum stress and diabetes mellitus. Intern Med. 2003;42:7-14.

15. Araki E, Oyadomari S, Mori M. Impact of endoplasmic reticulum stress pathway on pancreatic b-cells and diabetes mellitus. Exp Biol Med. 2003;228:1213-7.

16. Mozzillo $E$, Delvecchio $M$, Carella $M$, et al. A novel CISD2 intragenic deletion, optic neuropathy and platelet aggregation defect in Wolfram syndrome type 2. BMC Med Genet. 2014;24:15-88.

17. Rohayem J, Ehlers C, Wiedeman B, et al. Diabetes and neurodegeneration in Wolfram syndrome. Diabetes Care. 2011;34:1503-10.

18. Oslowski CM, Urano F. A switch from life to death in endoplasmic reticulum stressed b-cells. Diabetes Obes Metab. 2010;12 (Suppl 2):58-65.

19. Ghirardello S, Dusi E, Castiglione B, et al. Congenital central diabetes insipidus and optic atrophy in a Wolfram newborn: is there a role for WFS1 gene in neurodevelopment? Int J Pediatr. 2014;26:40-76.

20. Cnop M, Foufelle F, Velloso LA. Endoplasmic reticulum stress, obesity and diabetes. Trends Mol Med. 2012;18:59-68.

21. Urano F. Wolfram syndrome iPS cells: the first human cell model of endoplasmic reticulum disease. Diabetes. 2014;63:844-6

22. Marshall BA, Permutt MA, Paciorkowski AR, et al. Phenotypic characteristics of early Wolfram syndrome. Orphanet J Rare Dis. 2013;27:8-64.

23. Urano F. Targeting endoplasmic reticulum to combat juvenile diabetes. Nat Rev Endocrinol. 2014;10:129-30.

24. Barret TG, Bundey SE, Macleod AF. Neurodegeneration and diabetes: UK nationwide study of Wolfram (DIDMOAD) syndrome. Lancet. 1995;346:1458-63.

25. Matsunaga $\mathrm{K}$, Tanabe $\mathrm{K}$, Inoue $\mathrm{H}$, et al. Wolfram syndrome in the Japanese population; molecular analysis of WFS1 gene and characterization of clinical features. PLoS One. 2014 Sep 11;9:e106906.

26. Ganie MA, Laway BA, Nisar S, et al. Short report: epidemiology, presentation and course of Wolfram (DIDMOAD) syndrome from North India. Diabet Med. 2011;28:1337-42.

27. Medlej R, Wasson J, Baz P, et al. Diabetes melitus and optic atrophy: a study of Wolfram syndrome in the Lebanese population. J Clin Endocrinol Metab. 2004;89:1656-61.

28. Domènech $E$, Gómez-Zaera $M$, Nunes V. Study of the WFS1 gene and mitocondrial DNA in Spanish Wolfram syndrome families. Clin Genet. 2004;65:463-9.

29. Chaussenot A, Rouzier C, Quere M, et al. Mutation update and uncommon phenotypes in a French cohort of 96 patients with WSF1-related disorders. Clin Genet. 2015;87:430-9. 
30. Gasparin MRR, Crispim F, Paula SL, et al. Identification of novel mutations of the WFS1 gene in Brazilian patients with Wolfram syndrome. Eur J Endocrinol. 2009;160:309-16.

31. Aloi C, Saina A, Pasquali L, et al. Wolfram syndrome: new mutations, different phenotype. PLoS One. 2012;7:e29150.

32. López de Heredia M, Clèries R, Nunez V. Genotypic classification of patients with Wolfram syndrome: insights into the natural history of the disease and correlation with phenotype. Genet Med. 2013;15:497-506.

33. Barret TG, Bundey SE. Wolfram (DIDMOAD) syndrome. J Med Genet. 1997;34:838-41.

34. Cano A, Molines L, Valero R, et al., and the French Group of Wolfram Syndrome. Microvascular diabetes complications in Wolfram syndrome (diabetes insipidus, diabetes mellitus, optic atrophy and deafness [DIDMOAD]): an age- and duration-matched comparison with common type 1 diabetes. Diabetes Care. 2007;30:2327-30.

35. Zmyslowska A, Fendler W. Szadkowska A, et al. Glycemic variability in patients with Wolfram syndrome is lower than in type 1 diabetes. Acta Diabetol. 2015:52:1057-62.

36. Barret TG, Bundey SE, Fielder AR, et al. Optic atrophy in Wolfram (DIDMOAD) syndrome. Eye. 1997;11:882-8.

37. Boutzios G, Lavadas S, Marinakis E, et al. Endocrine and metabolic aspects of the Wolfram syndrome. Endocrine. 2011:40:10-3.

38. Smith CJA, Crock PA, King BR, et al. Phenotype-genotype correlations in a series of Wolfram syndrome families. Diabetes Care. 2004;27:2003-9.

39. Gabreels BA, Swaab DF, De Kleijn DP, et al. The vasopressin precursor is not processed in the hypothalamus of Wolfram syndrome patients with diabetes insipidus: evidence of the involvement of PC2 and 7B2. J Clin Endocrinol Metab. 1998:83:4026-33.

40. Simsek E, Simsek T, Tekgül S, et al. Wolfram (DIDMOAD) syndrome: a multidisciplinary clinical study in nine Turkish patients and review of the literature. Acta Paediatr. 2003;92:55-61.

41. van ven Ouweland JM, Cryns K, Pennings RJ, et al. Molecular characterization of WFS1 in patients with Wolfram syndrome. J Mol Diagn. 2003;5:88-95

42. Pennings RJE, Bom SJH, Cryns K, et al. Progression of low-frequency sensorineural hearing loss (DFNA6/14-WFS1). Arch Otolaryngol Head Neck Surg. 2003;129:421-6.

43. Homa K, Stefanski A, Zmylowska A, et al. False diagnosis of type 1 diabetes mellitus and its complications in Wolfram syndrome -is it the reason for the low number of reported cases in this anormality? Endokrynologia Polska. 2014;65:5

44. Chaussenot A, Bannwarth S, Rouzier C, et al. Neurologic features and genotype-phenotype correlation in Wolfram syndrome. Ann Neurol. 2011;69:501-8.

45. Waschbisch A, Volbers B, Struffert T, et al. Primary diagnosis of Wolfram syndrome in an adult patient - case report and description of a novel patogenic mutation. J Neurol Sci. 2011;300:191-3.
46. Hershey T, Lugar HM, Shimony JS, et al. Early brain vulnerability in Wolfram syndrome. PLoS One. 2012;7:e40604.

47. Mathis S, Maisonobe T, Neau JP. Neuropathy in Wolfram syndrome. Eur J Med Genet. 2011;54:73-5.

48. Pickett KA, Duncan RP, Paciorkowski AR, et al. Balance impairment in individuals with Wolfram syndrome. Gait Posture. 2012;36:619-24.

49. Swift M, Swift RG. Psychiatric disorders and mutations at the Wolfram syndrome locus. Biol Psychiatry. 2000;47:787-93.

50. Sequeira A, Kim C, Seguin M, et al. Wolfram syndrome and suicide: evidence for a role of WFS1 in suicidal and impulsive behavior. Am J Med Gen B Neuropsychiatr Genet. 2003;119:108-13.

51. Kytövuori L, Seppänen A, Martikainen MH, et al. WFS1 variants in Finnish patients with diabetes mellitus, sensorineural hearing impairment or optic atrophy, and in suicide victims. J Hum Genet. 2013;58:495-500.

52. Sobhami M, Tabatabaifar MA, Rajab A, et al. Significant expressivity of Wolfram syndrome: phenotypic assesement of two known and one novel mutation in the WFS1 gene in three Iranian families. Mol Biol Rep. 2014:41:7499-505.

53. Haghighi A, Haghighi A, Setoodeh A, et al. Identification of homozygous WFS1 mutations (p.Asp211Asn, p.Gln486*) causing severe Wolfram syndrome and first report of male fertility. Eur J Hum Genet. 2013;21:347-51.

54. Lui Z, Sakakibara R, Uchiyam T, et al. Bowel dysfunction in Wolfram syndrome. Diabetes Care. 2006;29:472-3.

55. Hardy C, Khanim F, Torres R, et al. Clinical and molecular genetic analysis of 19 Wolfram syndrome kindreds demonstrating a wide spectrum of mutations in WFS1. Am J Hum Genet. 1999;65:1279-90.

56. D'Annunzio G, Minuto N, D'Amato E, et al. Wolfram syndrome (diabetes insipidus, diabetes, optic atrophy, and deafness). Clinical and genetic study. Diabetes Care. 2008;31:1743-45

57. Cryns K, Sivakumaran TA, Van den Ouweland JM, et al. Mutational spectrum of the WFS1 gene in Wolfram syndrome, nonsyndromic hearing impairment, diabetes mellitus and psychiatric disease. Human Mutation. 2003;22:275-87.

58. Yu G, Yu M, Wang J, et al. WS1 gene mutation analysis of Wolfram syndrome in a Chinese patient and a systematic review of literature. Endocrine. 2010;38:147-52.

59. Sobhani M, Tabatabaiefar MA, Rajab A, et al. Molecular characterization of WFS1 in an Iranian family with Wolfram syndrome reveals a novel frameshift mutation associated with early symptoms. Gene. 2013; 528:309-13.

60. Zenteno JC, Ruiz G, Pérez-Cano HJ, et al. Familial Wolfram syndrome due to compound heterozygosity for two novel WFS1 mutations. Mol Vis. 2008;14:1353-7.

61. Blanco-Aguirre ME, la Parra DR, Tapia-Garcia $\mathrm{H}$, et al. Identification of unsuspected Wolfram syndrome cases through clinical assessment and WFS1 gene screening in type 1 diabetes mellitus patients. Gene. 2015;15:63-7. 